\title{
Pyrexia of unknown origin: changing spectrum of diseases in two consecutive series
}

\author{
F.J. Barbado, J.J. Vázquez, J.M. Peña, F. Arnalich and J. Ortiz-Vázquez \\ Department of Internal Medicine, La Paz University Hospital, Autonoma University, Madrid, Spain
}

\begin{abstract}
Summary: Comparison was made of the aetiology and methods of diagnosis in two series of patients meeting the classic criteria of pyrexia of unknown origin during 1968-1981 and during 1982-1989 seen in the Department of Internal Medicine at La Paz University Hospital, Madrid, Spain. There was a statistically significant decrease in the percentage of infections and an increase in neoplasms and connective tissue disorders in the second series. The percentage of patients diagnosed by laparatomy was similar in both series but the diagnosis yield at laparotomy was greater in the second period. Pyrexia of unknown origin continues to be a condition which can defy clinical expertise in spite of advances in diagnostic techniques.
\end{abstract}

\section{Introduction}

Pyrexia of unknown origin (PUO) continues to be one of the most challenging situations facing the physician. ${ }^{1-3}$ Since Petersdorf's and Beeson's classic study in $1961^{4}$ the profile of patients with unexplained fever has evolved as a result of changes in the broad spectrum of diseases causing FUO and the availability of new diagnostic techniques. ${ }^{5-8}$ Knowledge of the current patterns of PUO is important since many patients present potentially treatable diseases and many of the procedures involved in the diagnosis of PUO are uncomfortable, time-consuming and expensive.

We previously published a series of cases of PUO seen from 1968 to $1981^{9}$ and now compare the aetiology and diagnostic methods with a second series of cases seen from 1982 to 1989.

\section{Patients and methods}

The study included patients meeting criteria of PUO admitted to the Department of Internal Medicine of La Paz Hospital, Madrid, Spain over the last 22 years $(1968-1989)$. This hospital is a 1,500 bed medical-surgical university centre which serves the medical needs of a community of 350,000 people and it is also a referral hospital of many regions of Spain. PUO was defined as a temperature greater than $38.3^{\circ} \mathrm{C}$ on several occasions, lasting for 3 weeks or longer and remaining undiag-

Correspondence: F.J. Barbado, M.D., C§ Eduardo Benot 5, $1^{\circ} \mathrm{D}, 28008$ Madrid, Spain.

Accepted: 19 May 1992

This study was supported, in part, by a grant from 'Caja de Ahorros de Madrid'. nosed after investigation for one week in the $\stackrel{5}{\rightarrow}$ hospital ${ }^{4}$ During this first week, the following were $Z$ done: clinical history; physical examination; com-? plete blood cell count, serum urea, creatinine, $\frac{\Phi}{3}$ glucose, liver enzymes, alkaline phosphatase; salmonella and brucella serology; blood cultures; urine and sputum microscopy and culture; PP skin test; and chest and abdominal X-ray filme ? Patients in whom the above tests failed to provide. diagnosis were further examined by immunological, bacteriological, radionuclide scanning and non-invasive imaging techniques. If no conclusive evidence of the cause of PUO was obtained by the $\stackrel{\varnothing}{\Phi}$ latter, patients underwent invasive methods includ- $\overrightarrow{\vec{P}}$ ing exploratory laparatomy.

Two time periods were analysed, the first from $\frac{3}{5}$ 1968 to $1981^{9}$ and the second from 1982 to 1989 in which ultrasonography testing was included during the first week work-up and further diagnostic 3 . methods were carried out in a protocolized sequence. In the second series, human immuno- 3 . deficiency virus (HIV) seropositive patients were $\delta$ excluded. Nearly all patients were seen by one of us (FJB).

A comparative analysis was made of the aetiology and diagnostic techniques. Differences in the incidence of the main causes of PUO were analysed using Pearson's chi-squares.

\section{Results}

The first series consisted of 133 subjects (72 males) $\stackrel{\varrho}{\frac{\varrho}{D}}$

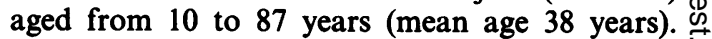
Fifty-five patients $(41 \%)$ were previously seen in 0 other medical centres. The second series was 85 을 subjects ( 32 males), aged from 14 to 91 years (mean: 
55 years). Thirty-eight patients $(45 \%)$ were referred from other hospitals.

An aetiological diagnosis was established in 105 patients $(79 \%)$ in the first series and $72(85 \%)$ in the second. Table I shows the illnesses causing PUO in both time periods.

In the earlier series infectious diseases were the most frequent cause of PUO. The 'other' infections included two cases each of rickettsioses and cholangitis and single cases of salmonellosis, yersiniosis, pyelonephritis, and hepatic hydatid cysts.

The second commonest cause was neoplastic diseases. There were 11 cases of Hodgkin's disease and five of non-Hodgkin's lymphoma, two of hepatocellular carcinoma, and one each with renal cancer, colon adenocarcinoma, anaplastic carcinoma, neuroblastoma, xanthofibrosarcoma and malignant histiocytosis.

The cases of vasculitis were polyarteritis nodosa $(n=10)$ and temporal arteritis $(n=4)$. The miscellaneous group included two cases each angio-

Table I Final diagnosis in 218 patients with PUO

\begin{tabular}{|c|c|c|}
\hline & $\begin{array}{c}\text { First series } \\
1968-1981 \\
(\mathrm{n}=133)\end{array}$ & $\begin{array}{c}\text { Second series } \\
1982-1989 \\
(\mathrm{n}=85)\end{array}$ \\
\hline Infections & $41(31 \%)$ & $9(11 \%)$ \\
\hline Tuberculosis & 15 & 8 \\
\hline Localized abscess & 4 & 0 \\
\hline Brucellosis & 4 & 0 \\
\hline Leishmaniasis & 3 & 1 \\
\hline Hepatic fascioliasis & 3 & 0 \\
\hline Endocarditis & 2 & 0 \\
\hline Other & 10 & 0 \\
\hline Tumours & $24(18 \%)$ & $24(28 \%)$ \\
\hline Lymphomas & 16 & 12 \\
\hline Solid & 7 & 10 \\
\hline Other & 1 & 2 \\
\hline $\begin{array}{l}\text { Collagen vascular } \\
\text { disorders }\end{array}$ & $17(13 \%)$ & $25(29 \%)$ \\
\hline Vasculitis & 14 & 19 \\
\hline Still's disease & 1 & 5 \\
\hline $\begin{array}{l}\text { Systemic lupus } \\
\text { erythematosus }\end{array}$ & 2 & 0 \\
\hline Other & 0 & 1 \\
\hline Miscellaneous & $23(17 \%)$ & $14(17 \%)$ \\
\hline Factitious fever & 6 & 3 \\
\hline Liver diseases & 3 & 2 \\
\hline $\begin{array}{l}\text { Idiopathic } \\
\text { granulomatosis }\end{array}$ & 1 & 2 \\
\hline Crohn's disease & 1 & 2 \\
\hline Other & 12 & 5 \\
\hline No diagnosis & $28(21 \%)$ & $13(15 \%)$ \\
\hline Self-limiting & 25 & 12 \\
\hline Persisting fever & 3 & 1 \\
\hline
\end{tabular}

immunoblastic lymphadenopathy and familial Mediterranean fever and one each with liver cirrhosis, chronic active hepatitis, alcoholic hepatitis, autoimmune haemolytic anemia, retroperitoneal haematoma, myelodysplastic syndrome, Reiter's syndrome, spondyloarthritis, subacute thyroiditis, xanthogranulomatous pyelonephritis and cryptogenic fibrosing alveolitis.

In the second series the most frequent diagnostic category was collagen vascular disease, encountered in 25 patients. There were 10 cases of temporal arteritis and nine of polyarteritis nodosa, five of Still's disease, and a single case of diffuse eosinophilic fascitis disease.

The next most frequent cause was neoplastic diseases. There were eight cases of Hodgkin's disease and four of non-Hodgkin's lymphoma. There were two cases each of renal cancer, colon adenocarcinoma, anaplastic carcinoma, and pancreatic carcinoma and one each with bronchogenic carcinoma, aleukaemic leukaemia, gastric neurinoma, and splenic hamartoma.

Of the eight cases of disseminated tuberculosis, the diagnosis was established at necropsy in three. In the miscellaneous group there were two cases of chronic active hepatitis and one each with idiopathic retroperitoneal fibrosis, seronegative spondylarthritis, Weber-Christian syndrome, De Quervain's thyroiditis and myelodysplastic syndrome.

There was a statistically significant difference in the percentage of infections $(P<0.05)$, neoplastic diseases $(P<0.05)$ and connective tissue disorders $(P<0.05)$ between the two series.

Figure 1 illustrates the methods used to establish final diagnosis in 177 patients. Invasive techniques were necessary in 116 patients $(65 \%)$, non-invasive methods were sufficient in $42(24 \%)$ and in the remaining 19 patients the responsible condition causing PUO was determined at autopsy. The percentage of patients diagnosed by laparotomy was almost identical but in the first series it was performed on 31 occasions providing a diagnosis in 21 cases $(68 \%)$. In the second series laparotomy was done in 17 cases, giving the diagnosis in 15 $(88 \%)$.

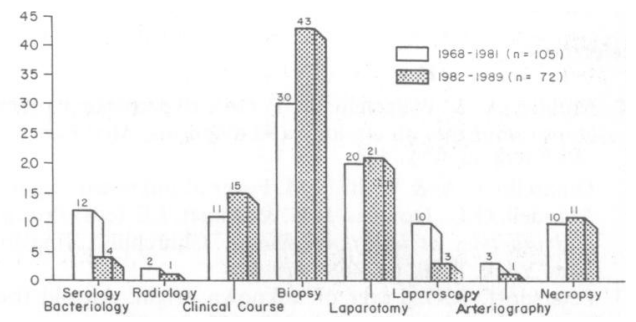

Figure 1 Method of final diagnosis in 177 patients with PUO 


\section{Discussion}

The patterns of admission and/or referral were the same throughout the two periods studied but in the second series the patients were older. In the eighties, the population that came to our hospital for whatever reason was older than in the seventies. Perhaps this explains the greater number of cases of temporal arteritis as well as the decrease in the self-limiting PUO which is characteristic of the younger patients found in the second series. The use of abdominal ultrasonography during the first week work-up in the second period explains the reduced number of disorders easily diagnosed by this technique such as liver, biliary and other abscesses. ${ }^{10,11}$ We excluded from the study HIVinfected patients with unexplained fever. This group has characteristics ${ }^{12}$ that distinguish it from the 'classic' PUO. ${ }^{13}$

In our first series, the 'big three' causes of PUO' were found within the range described at that time by other authors: infection (30-40\%), neoplastic diseases $(20-30 \%)$, and collagen vascular disease $(10-15 \%))^{1,4,14-18}$

In our second series, the most frequent cause of PUO was collagen vascular disease in particular systemic vasculitides. As noted by Knockaert et al. ${ }^{8}$ temporal arteritis was the single most important cause of PUO. Thus, it would be wise to perform a temporal artery biopsy in an elderly patient with persistent and perplexing fever. Still's disease was more frequently found in the second series perhaps because it is solely diagnosed on a clinical basis when other diseases are excluded. ${ }^{19}$ In contrast, because of the availability of serological tests, today systemic lupus erythematosus is an exceptional cause of PUO.,8

The series of Larson et al. ${ }^{5}$ was the first one containing more patients with neoplastic disease than infections. Our experience is similar with the latter but it contrasts with the substantially lower number of tumours found in a recent report ${ }^{8}$ which the authors suspect was due to the widespread use of computed tomography. As they used it in $83 \%$ of their patients and we in $87 \%$, this does not appear to explain the difference.

\section{References}

1. Molavi, A. \& Weinstein, L. Persistent perplexing pyrexia: some comments on etiology and diagnosis. Med Clin North Am 1970, 54: 379-396.

2. Dinarello, C.A. \& Wolff, S.M. Fever of unknown origin. In: Mandell, G.L., Douglas, R.G. \& Bennet, J.E. (eds) Principles and practices of infections disease. Churchill Livingstone, New York, 1990, pp. 468-479.

3. Petersdorf, R.G. Fever of unknown origin. An old friend revisited. Arch Intern Med 1992, 152: 21-22.

4. Petersdorf, R.G. \& Beeson, P.B. Fever of unexplained origin: report of 100 cases. Medicine (Baltimore) 1961, 40: 1-30.
PUO of infectious origin significantly decreased $\stackrel{๊}{2}$ in the second period and was almost exclusively $\frac{\$}{\infty}$ caused by tuberculosis. This could be due to a

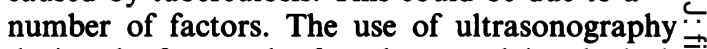
during the first week of work-up explains the lack $\underset{\overrightarrow{2}}{\overrightarrow{2}}$ of abdominal abscess and certain hepatobiliary diseases; echocardiography and improved bac- $\overline{0}$ teriological techniques perhaps explain why no $\overline{\frac{\bar{F}}{\sigma}}$ cases of endocarditis presented as PUO. ${ }^{20} \widetilde{\otimes}$ Similarly, other bacterial infections such as brucellosis are less frequently associated with PUO than ${ }^{\infty}$ in the past. ${ }^{5}$ Nowadays other infections, mainly of $\vec{O}$ viral origin including cytomegalovirus or chronic $\overrightarrow{\vec{\omega}}$ Epstein-Barr virus infections, are more preva- $\omega$ lent. ${ }^{7,821}$ In agreement with other authors, diag- -0 nosis of factitious fever, chronic active hepatitis, 3 Crohn's disease and idiopathic granulomatosis were prominent amongst the miscellaneous causes $\stackrel{\infty}{\infty}$ of PUO.22-24

With regard to the diagnostic methods used in cases of PUO, biopsy (including those done under $\stackrel{\infty}{\perp}$ direct laparoscopic vision ${ }^{25}$ ) and exploratory 을 laparotomy continue to stand out as procedures of great value. These observations agree with Lar- $Z$ son's findings $s^{5}$ that exploratory surgery and histological examination of tissue were necessary to a $\frac{\Phi}{3}$ similar degree in their first and second series, $\underset{\mathbb{\Phi}}{\mathbb{D}}$ despite considerable advances in diagnostic techn? ques.

In the second period, laparotomy was almosi ? exclusively done when abnormal computed tom $\overline{\sigma^{*}}$ 망 graphic findings were seen and we obtained only a few normal laparotomies. Thus, computed tomography would be a valuable adjuvant diagnostic tool.

Pyrexia of unknown origin continues to be a $\vec{F}$ clinical condition which defies technical advances in diagnostic modalities and the expertise of the clinical physician.

\section{Acknowledgement}

The authors are grateful to Marta Pulido, M.D. and Jacqueline Uson, M.D. for editorial assistance and copy editing.

5. Larson, E.B., Featherstone, H.J. \& Petersdorf, R.G. Fever of N undetermined origin: diagnosis and follow-up of 105 cases $N$ 1970-1980. Medicine (Baltimore) 1982, 61: 269-291.

6. Welsby, P.D. Pyrexia of unknown origin sixty years on. Postgrad Med J 1985, 61: 887-894.

7. Brush, J.L. \& Weinstein, L. Fever of unknown origin. Med Clin North Am 1988, 72: 1247-1261.

8. Knockaert, D.C., Vanneste, L.J., Vaneste, S.B. \& Bobbaers, H.J. Fever of unknown origin in the 80s: an update of the diagnostic spectrum. Arch Intern Med 1992, 152: 52-55. 
9. Barbado, F.J., Vázquez, J.J., Peña, J.M. et al. Fever of unknown origin: a survey of 133 patients. J Med 1984, 15: 185-192.

10. Gaspar, G., Barbado, F.J., Redondo, C., Vázquez, J.J., Peña, J.M. \& y Segura, J.M. Valor diagnóstico de la ultrasonografia abdominal en la fiebre de origen desconocido. Med Clin (Barcelona) 1981, 77: 153-157.

11. Rustgi, A.K., Saini, S. \& Schapiro, R.H. Hepatic imaging and advanced endoscopic techniques. Med Clin North Am 1989, 73: 895-909.

12. Prego, V., Glatt, A.E., Roy, V., Thelmo, W., Dincsoy, H. \& Raufman, J.-P. Comparative yield of blood culture for fungi and mycobacteria, liver biopsy and bone marrow biopsy in the diagnosis of fever of undetermined origin in human immunodeficiency virus-infected patients. Arch Intern Med 1990, 150: 333-336.

13. Durack, D.T. \& Street, A.C. Fever of unknown origin: reexamined and redefined. In: Remington, J.S. Swartz, Mn. (eds) Current Clinical Topics in Infectious Diseases. Blackwell Scientific Publications, Boston, 1991, 11: 35-51.

14. Vickery, D.H. \& Quinnell, R.K. Fever of unknown origin. An algorithmic approach. JAMA 1977, 238: 2183-2188.

15. Howard, P., Hahn, H., Palmer, R.L. \& Hardin, W.L. Fever of unknown origin: a prospective study of 100 patients. Tex Med 1977, 73: 53-59.

16. Deal, W.B. Fever of unknown origin. Analysis of 34 patients. Postgrad Med 1971, 50: 182-188.
17. Moya Mir, M.S., Barbadillo, R., Mosquera, J.M. \& González, M.-L. Fiebre de origen desconocido. Analisis de 58 casos. Rev Clin Esp 1976, 141: 119-130.

18. Esposito, A.L. \& Gleckman, R.A. Fever of unknown origin in the elderly. $J$ Am Geriatr Soc 1978, 26: 498-505.

19. Pouchot, J., Samplis, J.S., Beaudet, F. et al. Adult Still's disease: manifestations, disease course and outcome in 62 patients. Medicine (Baltimore) 1991, 70: 118-136.

20. Naggar, C.Z. \& Forgacs, P. Infective endocarditis: a challenging disease. Med Clin North Am 1986, 70: 1279-1294.

21. Smith, J.W. Fever of undetermined origin: not what used to be. Am J Med Sci 1986, 292: 56-64.

22. Aduan, R.P., Fauci, A.S., Dale, D.C., Herzberg, J.H. \& Wolff, S.M. Factitious fever and self-induced infection. A report of 32 cases and review of the literature. Ann Intern Med 1979, 90: 230-242.

23. Telenti, A. \& Hermans, P.E. Idiopathic granulomatosis manifesting as fever of unknown origin. Mayo Clin Proce 1989, 64: 44-50.

24. Lee, F.I. \& Davis, D.M. Crohn's disease presenting a pyrexia of unknown origin. Lancet 1961, i: 1205.

25. Solis-Herruzo, J.A., Benita, V. \& Morillas, J.D. Laparoscopy in fever of unknown origin. Study of seventy cases. Endoscopy 1981, 13: 207-210. 